\title{
MENERAPKAN APLIKASI GIS UNTUK MENGETAHUI LOKASI DAN KEBUTUHAN SEKOLAH (Studi Kasus di Dinas Pendidikan Mukomuko)
}

\author{
Radius Prawiro ${ }^{1}$, Azrai Sirait ${ }^{2}$ \\ ${ }^{1}$ Universitas Putra Indonesia “YPTK” Padang \\ J1. Lubuk Begalung No.1 Padang, kode pos 25221, Indonesia \\ ${ }^{2}$ Program Studi Teknik Informatik, Fakultas Teknik, Universitas Asahan \\ Kisaran, Indonesia \\ rcradius2210@gmail.com 2azraijhonegmail.com
}

\begin{abstract}
Abstrak - Isi penelitian ini adalah pembangunan Sistem Informasi Geografis. Pembangunan Sistem Informasi Geografis ini diharapkan dapat membantu Dinas Pendidikan untuk mendata kebutuhan sekolah yang ditampilkan dalam bentuk peta. Selain itu membantu masyarakat untuk mengetahui lokasi dan kebutuhan sekolah. Sistem Informasi Geografis ini ditampilkan dalam bentuk web sehingga setiap orang dapat mengaksesnya. Dalam membangun Sistem Informasi Geografis ini, penulis menggunakan google maps untuk menentukan titik koordinat. Titik koordinat ini adalah titik latitude dan longitude yang terdapat di google maps. Dengan menggunakan titik koordinat ini, akan di dapatkan lokasi sekolah. Nilai latitude dan longitude akan disimpan ke dalam database mysql dan akan dipanggil dengan menggunakan pemrograman php. Sistem Informasi Geografis ini dapat berjalan secara lokal yaitu menggunakan server lokal seperti XAMPP dengan ketentuan harus terkoneksi ke internet. Perancangan Sistem Informasi Geografis ini menggunakan pemodelan UML yang terdiri dari usecase, aktivitas diagram, kelas diagram, sekuensial diagram, statechart diagram, package diagram, komponen diagram, deployment diagram, dan kolaborasi diagram.
\end{abstract}

Kata Kunci - Sistem Informasi Geografis, Google Maps, Latitude, Longitude, UML

\section{PENDAHULUAN}

Pendidikan merupakan aspek penting untuk kemajuan suatu negara.Semakin banyaknya sekolah di Kabupaten Mukomuko sehingga akan sulit untuk Dinas Pendidikan Kabupaten Mukomuko mengecek kebutuhan sekolah. Sulitnya masyarakat untuk mencari lokasi sekolah dan sulitnya masyarakat mengetahui fasilitas apa saja yang ada di sekolah tersebut.

\section{LANDASAN TEORI}

A.

Sistem Informasi Geografis

Sistem Informasi Geografis atau sering disingkat dengan SIG merupakan suatu sistem berbasis komputer yang digunakan untuk mengumpulkan, menyimpan, mengatur, mentransformasi, menganalisis data-data geografis.

\section{Cara Kerja SIG}

SIG dapat merepresentasikan realworld (dunia nyata) di atas monitor komputer sebagaimana lembaran peta dapat merepresentasikan dunia nyata diatas kertas. Namun SIG memiliki kekuatan lebih dan fleksibilitas daripada lembaran peta kertas. Peta merupakan representasi grafis dari dunia nyata, objek-objek yang direpresentasikan diatas peta disebut unsure peta atau mapfeatures (contohnya adalah sungai, kebun, jalan, dan lain-lain). Karena peta mengorganisasikan unsur-unsur berdasarkan lokasi-lokasinya, peta sangat baik dalam memperlihatkan hubungan atau relasi yang dimiliki oleh unsur-unsurnya (Harseno dan Tampubolon, 2007).

\section{Pemanfaatan SIG}

Saat ini teknologi geospasial merupakan bagian standar dari operasi pengelolaan sumber daya alam dan perhutanan. Hal ini didukung oleh perkembangan perangkat keras geospasial seperti Global Positioning Systems (GPS), instrumen pengukuran digital, teknologi penginderaan jauh dan peralatan digital lainnya seperti plotter, GPS mobile dan lain sebagainya. Perangkat lunak SIG seperti Mapinfo, Arcview, Arcsgis dan Quantum GIS merupakan system perangkat lunak yang sangat mudah untuk diterapkan ke berbagai aspek pengelolaan lingkungan termasuk pada aspek manajemen dan penataan ruang (Agus, 2012). 3. Arsitektur Sistem Informasi Geografis
Berbasis Web

Penelitian ini menggunakan arsitektur SIG berbasis web yang digunakan untuk menggambarkan bagaimana proses informasi bisa sampai kepada masyarakat.

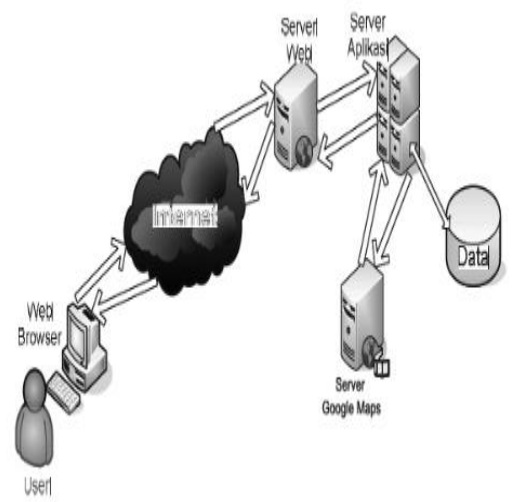

Gambar 1 Arsitektur SIG berbasis web 


\section{B. $\quad$ UML (Unified Modeling Language)}

UML (Unified Modelling Language) adalah sebuah bahasa yang telah menjadi standard dalam industri visualisasi, merancang dan mendokumentasikan sistem perangkat lunak.

UML terdiri dari banyak komponen seperti use case diagram, object diagram, sequence diagram, collaboration diagram, class diagram, statechart diagram, activity diagram, component diagram, dan deployment diagram.

\section{METODE PENELITIAN}

\section{A. Kerangka Kerja Penelitian (framework)}

Di bab ini akan diuraikan kerangka kerja dan metodologi yang dipakai dalam menyelesaikan penelitian ini. Kerangka kerja adalah langkah-langkah yang harus dilakukan dalam penyelesaian penelitian.

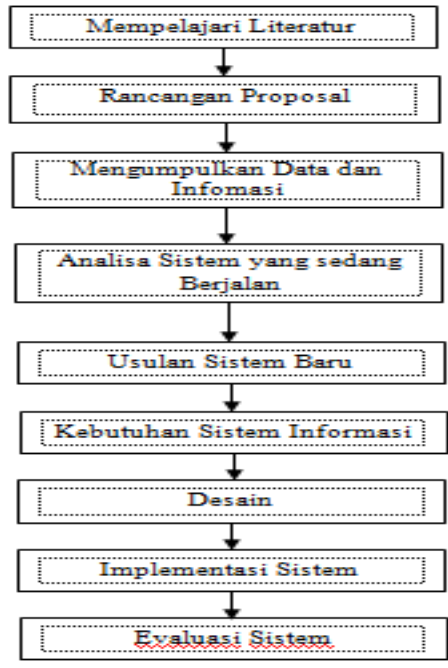

Gambar 2 Kerangka kerja

\section{ANALISA DAN PERANCANGAN SISTEM}

\section{A. Pengumpulan Data}

Tahapan pengumpulan data dilakukan dengan cara mengumpulkan data-data sekolah, data-data sekolah dimulai dari data Sekolah Dasar (SD), Sekolah Menengah Pertama (SMP), Sekolah Menengah Atas (SMA) dan Sekolah Menengah Kejuruan (SMK). Pengumpulan data-data sekolah ini dilakukan dengan cara mendatangi Dinas Pendidikan Kabupaten Mukomuko. Data-Data yang dikumpulkan antara lain :
a. Nama sekolah
b. Alamat sekolah
c. Prasarana sekolah
d. Jumlah guru
e. Keterangan

\section{B. Analisis Data}

Data-data sekolah yang sudah terkumpul dari Dinas Pendidikan akan dikelompokkan menjadi 4 kelompok yaitu kelompok Sekolah Dasar (SD) yang akan diberi ikon balon berwarna merah pada peta, Sekolah Menengah Pertam (SMP) yang akan diberi ikon balon berwarna biru pada peta. Sekolah Menengah Atas (SMA) yang akan diberi ikon berwarna kuning pada peta dan Sekolah Menengah Kejuruan (SMK) akan diberi ikon balon berwarna hijau. Ikon-ikon yang berwarna berbeda ini yang menentukan sekolah tersebut apakah Sekolah Dasar, Sekolah Menengah Pertama, Sekolah Menengah Atas atau Sekolah Menengah Kejuruan.

\section{C. $\quad$ Analisis Sistem}

Tahapan analisis sistem ini merupakan tahapan penggambaran kerja sistem secara umum. Cara kerja sistem ini dimulai dari tahapan di mana sekolah mulai mengisi data nama sekolah, alamat sekolah, prasarana sekolah, jumlah guru dan keterangan.

\section{Perancangan Sistem}

Tahapan perancangan sistem ini dimulai dari perancangan model dan perancangan input. Perancangan model ini menggunakan UML Perancangan input akan menggambarkan kerangka aplikasi SIG yang akan dibuat.

1. Perancangan Use case Diagram

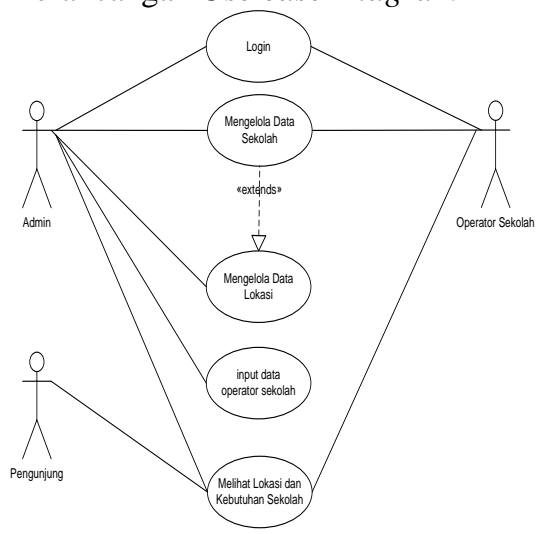

Gambar 2 Use case Diagram Sistem Informasi Geografis

2 Perancangan Activity Diagram
Pengunjung, Admin, Web Browser $\quad$ Web Server
$\begin{aligned} & \text { Operator Sekolah } \\ & \text { Google Server }\end{aligned}$

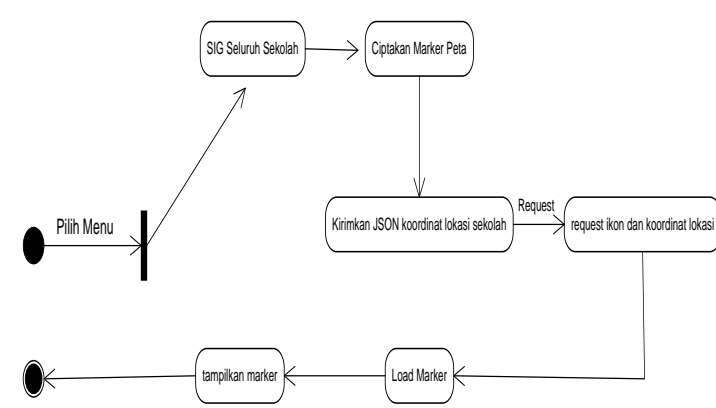

Gambar 3 Activity Diagram Lokasi dan Kebutuhan Sekolah 

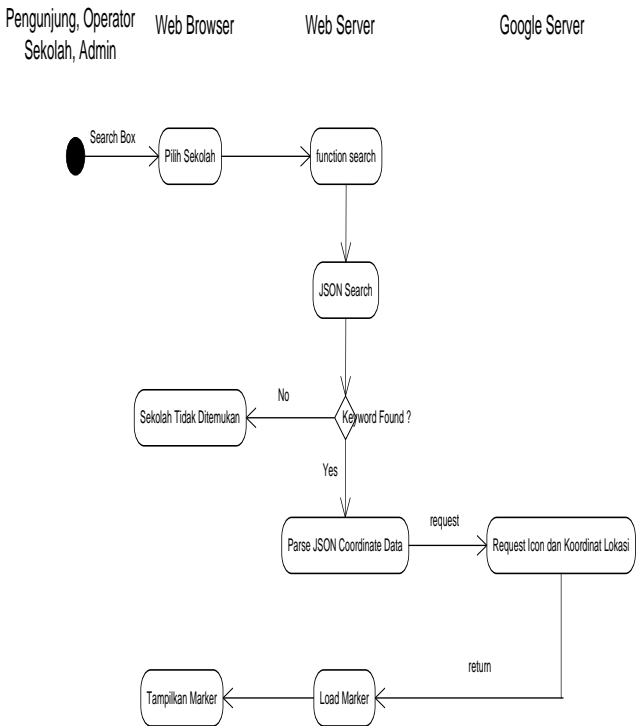

Gambar 4 Activity Diagram Untuk Mencari Lokasi dan Kebutuhan Sekolah

3 Perancangan Class Diagram

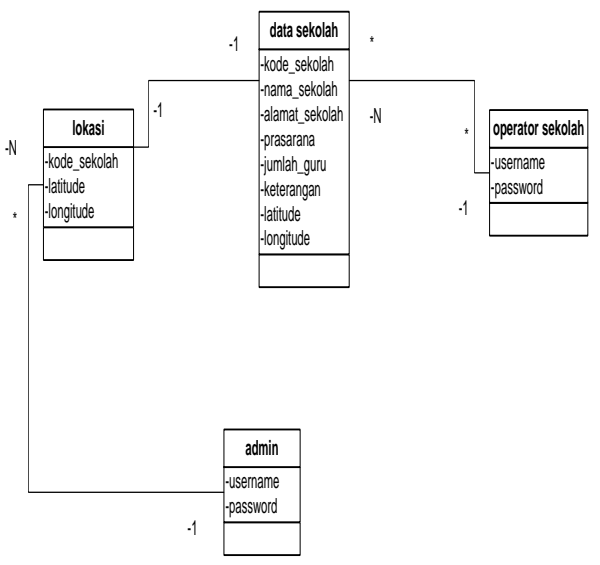

Gambar 5 Class Diagram Sistem Informasi Geografis $4 \quad$ Perancangan Sekuence Diagram

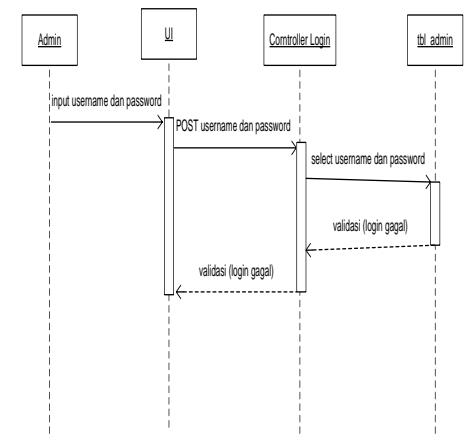

Gambar 6 Sekuence Diagram Login Admin

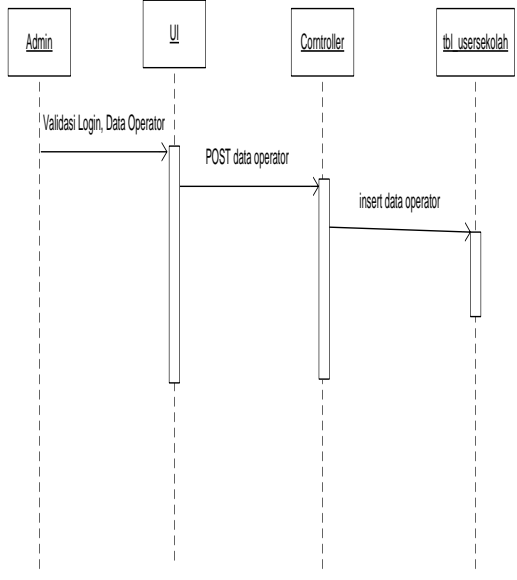

Gambar 7 Sekuence Diagram Input User Operator Sekolah

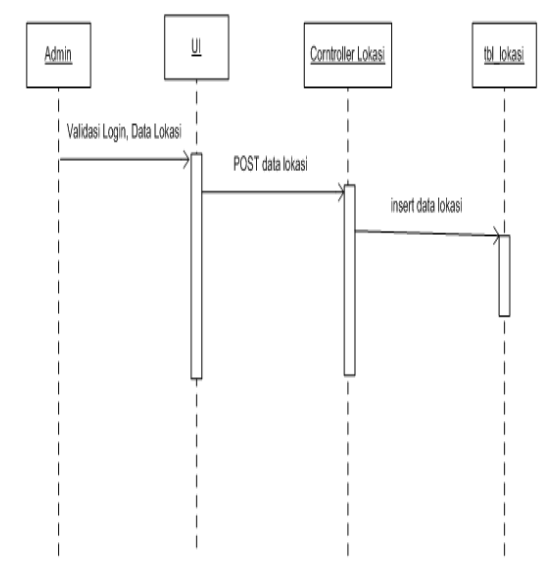

Gambar 8 Sekuence Diagram Lokasi

\section{IMPLEMENTASI DAN PENGUJIAN SISTEM}

A. Tampilan Halaman Depan (Front End)

Halaman depan merupakan halaman tampilan Website Sistem Informasi Geografis. Tampilan halaman depan ini merupakan tampilan yang dapat diakses oleh seluruh pengunjung tidak memperhatikan apakah level user ataupun level admin. Pengunjung umum juga dapat mengakses halaman depan website ini. Berikut tampilan halaman depan (front end). 


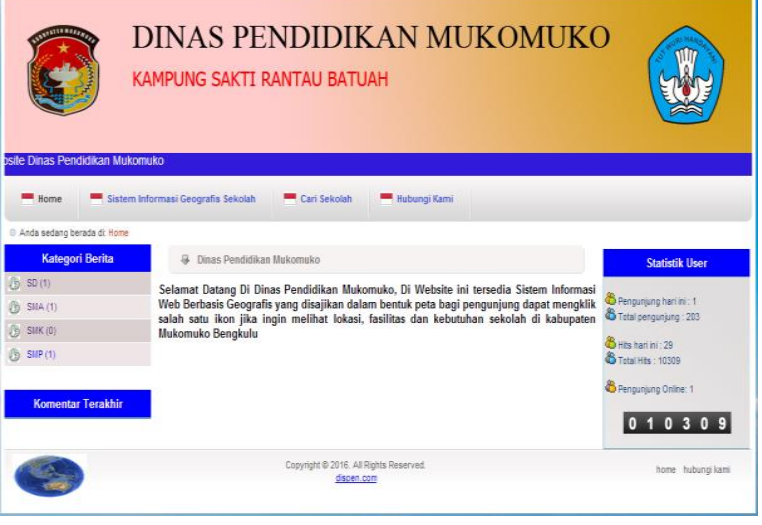

Gambar 9 Form Halaman Utama Website

Untuk melihat Sistem Informasi Geografis Sekolah klik menu Sistem Informasi Geografis. Selanjutnya akan tampil peta Sistem Informasi Geografis sekolah yang terdiri dari ikon-ikon berwarna merah untuk sekolah SD, biru untuk sekolah SMP, hijau, kuning untuk SMA dan hijau untuk SMK. Tampilan form Sistem Informasi Geografis adalah sebagai berikut.

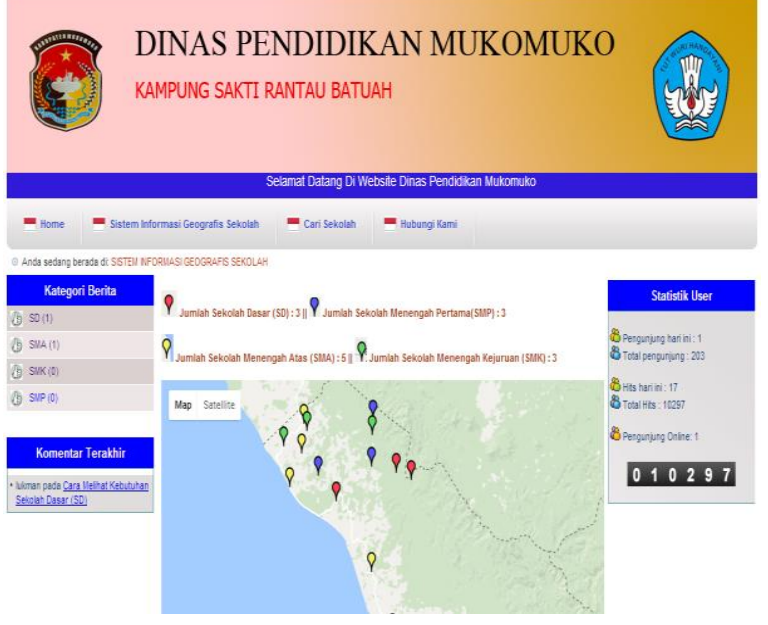

Gambar 10 Tampilan SIG Seluruh Sekolah

Gambar 10 tersebut adalah tampilan sekolah secara keseluruhan. Untuk mencari lokasi dan kebutuhan sekolah tertentu, maka pengunjung harus mengklik menu cari sekolah, sehingga akan tampil cari sekolah seperti terlihat pada gambar di bawah ini.

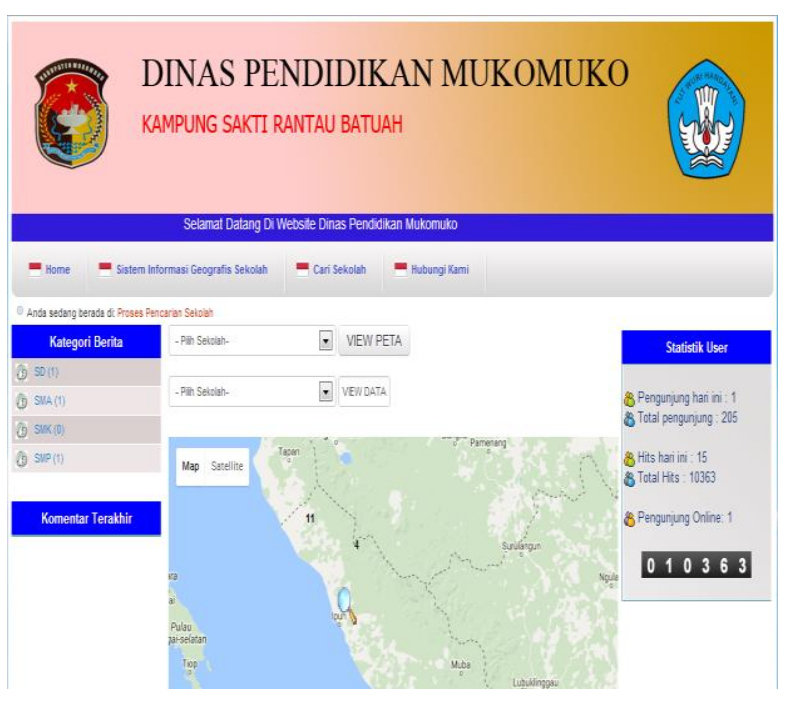

Gambar 11 Tampilan SIG Untuk Pencarian Lokasi dan Kebutuhan Sekolah

\section{KESIMPULAN DAN SARAN}

\section{A. Kesimpulan}

Berdasarkan penelitian dan pembahasan yang dilakukan, maka dapat disimpulkan beberapa hal sebagai berikut :

1. Rancangan Sistem Informasi Geografis juga dapat membantu pengunjung untuk mendapatkan informasi dan peta tentang lokasi dan kebutuhan sekolah.

2. Sistem Informasi Georafis yang dirancang dapat terlihat bahwa goole map dapat dihubungkan dengan database model relasional sehingga kita dapat membuat peta untuk wilayah yang kita kendali dan kebutuhan akan informasi yang ingin sekaligus mendapatkan letaknya di peta.

3. Dengan menerapkan Sistem Informasi Georafis dapat meningkatkan performance kerja dan mempermudah Dinas Pendidikan Mukomuko dalam mempersiapkan informasi yang dibutuhkan oleh masyarakat.

B. Saran

Berikut ini beberapa saran untuk pengembangan Sistem Informasi Geografis ini agar lebih baik :

1. Untuk pengembangan dalam Sistem Informasi Geografis yang penulis buat, sebaiknya tidak hanya menggunakan google map coba dikembangkan dengan menggunakan map info atau software pemataan yang lain dan hubungkan dengan database.

2. Sistem Informasi Geografis yang penulis buat sebaiknya dibuat pencariannya lokasi sekolah dengan menampilkan seluruh kebutuhan sekolah jika maker diklik. 


\section{DAFTAR PUSTAKA}

[1] Ardi Dwi Saputra I.S dan Yulmaini, (2012). “ Perancangan Sistem Informasi Geografis (Sig) Pariwisata Di Provinsi Lampung". Lampung : Darmajaya

[2] Edi Iskandar dan Sri Hartati, (2012). “ Jurnal Sistem Informasi Geografis Untuk Pemetaan Daerah Rawan Gempa Tektonik dan Jalur Evakuasi Di Yogyakarta". Yogyakarta : STMIK El Rahma

[3] Haviluddin , (2011). " Memahami Penggunaan UML (Unified Modelling Language)". Samarinda : Universitas Mulawarman

[4] Imairi Eitiveni dan Dana Indra Sensuse, 2012. "Implementation of Tile Based Geographic Information System in Indonesia EGovernment" . Vol. 9, Issue 5, No 2, September 2012

[5] Jakimi dan M. El Koutbi, (2009). “ An ObjectOriented Approach to UML Scenarios Engineering and Code Generation." Vol. 1, No. 1, April 2009.

[6] Lee, Sunguk, 2012. “ International Journal Unified Modelling Language (UML) for Database System and Computer Applications." Vol. 5, No. 1, March 2012.

[7] Lukito, Herwin, (2012). "pembangunan data base jaringan jalan berbasis Geospasial di kabupaten bengkalis". UPN Veteran. Tesis

[8] Pardede, F.A. dan Warnars S. (2012). "Pemanfaatan Teknologi Sistem Informasi Geografis Untuk Menunjang Pembangunan Daerah."Pelita Informatika Budi Darma. 2. hlm 1-6.

[9] Prahasta, E. (2002). "Sistem Informasi Geografis : Tutorial Arcview". Informatika,Bandung.

[10] Rosihan Ari Yuana, (2011). “67 Trik dan Ide Brilian Master PHP” Yogyakarta : Lokomedia

[11] Sholiq, (2006). "Pemodelan Sistem Informasi Berorientasi Objek dengan UML." Yogyakarta : Graha Ilmu.

[12] Wiria Nugraha, 2012. "Perancangan Sistem Informasi Geografis Menggunakan Peta Digital." Vol. 2, No. 1, 2012.

[13] Yuni Sugiarti, (2013). “Analisis dan Perancangan UML (Unified Modeling Language) Generated VB. 6." Yogyakarta : Graha Ilmu.Volume 14, No. 1, Juni 2012. 